\title{
Percepção ambiental no entorno da Floresta Nacional de Ritápolis
}

\section{The environmental perception in the surroundings of Ritápolis National Forest}

\author{
Arlon Cândido Ferreira \\ Geógrafo, Doutorando em Geografia, UFF, Brasil \\ arloncf@gmail.com \\ Filipe César Pereira \\ Geógrafo, Mestre em Geografia, UFSJ, Brasil \\ fylipecesar@hotmail.com
}

Ivair Gomes

Geógrafo, Professor do Departamento de Geociências, UFSJ, Brasil

ivair@ufsj.edu.br

Luiz Renato Vallejo

Biólogo, Professor Titular do Programa de Pós-Graduação em Geografia, UFF, Brasil luizrenato@id.uff.br

\begin{abstract}
Resumo
As unidades de conservação são unidades com fins preservacionistas. Mas qual seria a relação, como vivem e o que pensam os moradores vizinhos a essas unidades? Tentando responder a esse questionamento esse artigo tem por objetivo entender como se dá a percepção ambiental dos moradores do entorno de uma unidade de conservação. Concluiu-se, dentre outras coisas, que os moradores entendem a necessidade de preservação e apoiam a existem da UC, mas que as penalidades e as restrições aplicadas a população são o maior fator de atrito e poderiam ser mitigadas se houvesse um maior diálogo entre as entidades fiscalizadoras e os moradores do entorno.
\end{abstract}

Palavras-chave: Unidades de Conservação; Percepção Ambiental; Floresta Nacional de Ritápolis.

\begin{abstract}
Conservation units are units for preservation purposes. However, what would be the relationship, how do they live and what to the neighbors neighboring these units think? Trying to answer this question, this article aims to understand how the environmental perception of the residents surrounding a conservation unit occurs. It was concluded, among other things, that the residents understand the need for preservation and support the existence of the UC, but that the penalties and restrictions applied to the population are the most significant attrition factor and could be mitigated if there was a greater dialogue between the communities. Inspection entities and surrounding residents.
\end{abstract}

Keywords: Conservation Units; Environmental Perception; Ritápolis National Forest. 


\section{INTRODUÇÃO}

Discursos relacionados à atual situação do planeta nos fazem questionar o modo de agir das sociedades urbano-industriais sobre os recursos naturais e as perdas irreversíveis na natureza (CULLEN et al., 2004; PRIMACK, 2000). A crise no modelo de exploração e uso dos recursos e o debate contínuo sobre a sustentabilidade impõe a necessidade de buscar novas alternativas, sem comprometer a qualidade da vida planetária.

Dentre as práticas humanas com objetivos preservacionistas, a criação de Unidades de Conservação (UC) tem ganhado força no mundo inteiro. As UC são espaços territoriais e seus recursos ambientais, incluindo as águas jurisdicionais com características naturais relevantes, legalmente instituídas pelo Poder Público, com objetivos de conservação e limites definidos sob regime especial de administração, a qual se aplica garantias adequadas de proteção (BRASIL, 2000).

No Brasil, para legislar e gerir as UC, o Ministério do Meio Ambiente implantou o Sistema Nacional de Unidades de Conservação (SNUC), em 2000. O SNUC define categorias, regula a criação, a gestão e de modo geral explicita a preocupação governamental para a necessidade de delimitar e conservar áreas com especificidades naturais que justifiquem seu tratamento diferenciado. A proteção de áreas naturais, por meio da criação de UC é considerada uma estratégia para a conservação em longo prazo. Essas áreas são elementos vitais para qualquer tática de conservação da biodiversidade, frente à crise socioambiental. Além disso, são áreas em que os processos ecológicos podem acontecer sem maiores intervenções antrópicas.

Acontece que no entorno das UC as atividades antrópicas continuam sendo realizadas. Então, para que haja uma boa gestão ambiental é necessário pensar não apenas na UC a ser preservada, mas nos impactos gerados pela sua criação.

\footnotetext{
Uma parte considerável de planejadores e gestores ambientais tem atuado como se o ser humano pudesse ser reduzido ou à sua dimensão de "homo economicus", ou àquela de homem puramente racional ou, ainda, àquela de "romântico e inocente". A complexidade do comportamento humano não é bem representada por nenhum desses reducionismos. Por isso mesmo, certo número de pesquisadores vem trabalhando, há alguns anos, com outra hipótese: a de que as aspirações, decisões e ações, individuais e coletivas, que os homens desenvolvem em relação ao ambiente em que vivem, podem ser avaliadas através de uma cuidadosa análise das atitudes, preferências, valores, percepções e imagens que a mente humana tem a capacidade de elaborar. Um grupo de intelectuais, que começa a crescer em todo o mundo e, também no Brasil, está convencido de que os estudos das percepções ambientais dos homens de hoje constituem a última e decisiva fronteira no processo de uma gestão mais eficiente e harmoniosa do ambiente (AMORIM FILHO. s/d; grifo nosso).
}

Com base no que foi exposto acima, a abordagem da Percepção Ambiental é de vital importância para o planejamento, criação e manutenção de uma UC, pois um dos principais desafios 
que se apresenta atualmente são as relações entre as populações instaladas ou em regiões limítrofes à essas áreas protegidas (ACSELAD, 2004; FERREIRA, 2004).

O pressuposto fundamental é a afirmação segundo a qual as pessoas se comportam no mundo real não a partir de um conhecimento objetivo desse mundo, mas com base nas imagens subjetivas dele (AMORIM FILHO; CARTER; KOHLSDORF, 1987).

A Percepção Ambiental permite analisar o conhecimento, os valores e as atitudes da população e/ou dos atores sociais em relação a uma determinada área (FERREIRA, 2005). Ela é formada por aspectos inerentes ao próprio indivíduo, como por exemplo, os aspectos educacionais e culturais, introduzidos pela sociedade; e os afetivos e sensitivos, que têm origens nas relações do observador com o ambiente.

Entendemos que a participação da comunidade é de suma importância no sucesso dos objetivos do SNUC, sendo o conhecimento da opinião e dos anseios dessas comunidades uma importante ferramenta para a conservação das unidades, principalmente onde essa relação é muito íntima (SILVA, et al., 2009).

Neste trabalho, a área estudada é a Floresta Nacional de Ritápolis (MG). Segundo o Instituto Chico Mendes (ICMBio), uma Floresta Nacional é:

[...] uma área com cobertura florestal de espécies predominantemente nativas, criadas com o objetivo básico de uso múltiplo sustentável dos recursos florestais e pesquisa científica, voltada para a descoberta de métodos de exploração sustentável destas florestas nativas. É permitida a permanência de populações tradicionais que habitam a área, quando de sua criação, conforme determinar o plano de manejo da unidade. A visitação pública é permitida, mas condicionada às normas especificadas no plano de manejo. A pesquisa é permitida e incentivada, sujeitando-se à prévia autorização do Instituto Chico Mendes (BIODIVERSIDADE, 2018).

A Floresta Nacional (FLONA) de Ritápolis situa-se em área integrante da Fazenda do Pombal, local de nascimento do mártir Alferes Joaquim José da Silva - o Tiradentes (GUIMARÃES et al., 2008). Esta importante propriedade foi tombada pelo Patrimônio Histórico em 1971, devido às ruínas da sede e do engenho da Fazenda do Pombal. Em 1999 foi transformada em Floresta Nacional, mediante o Decreto de 21 de setembro de 1999, sendo atualmente administrada pelo Instituto Chico Mendes de Conservação da Biodiversidade (ICMBio).

Pertencente ao município de Ritápolis, na mesorregião do Campo das Vertentes, a FLONA está localizada na divisa dos municípios de Ritápolis, São João del-Rei e Coronel Xavier Chaves, aos $21^{\circ} 03^{\prime} 30^{\prime \prime}$ de latitude Sul e 4416'25" de longitude Oeste (Figura 1). Sua área total é de 89,50 hectares. Sua divisão atual compreende 36,94 ha de floresta estacional semidecidual, 25,93 ha de campo sujo e cerrado, 2 ha de reflorestamento com espécies Eucalyptus saligna, 8,75 ha de área de 
empréstimo e de bota fora, 5,51 ha de sede administrativa e 10,03 ha utilizada pela ferrovia que corta a UC (FERREIRA, et al., 2016).

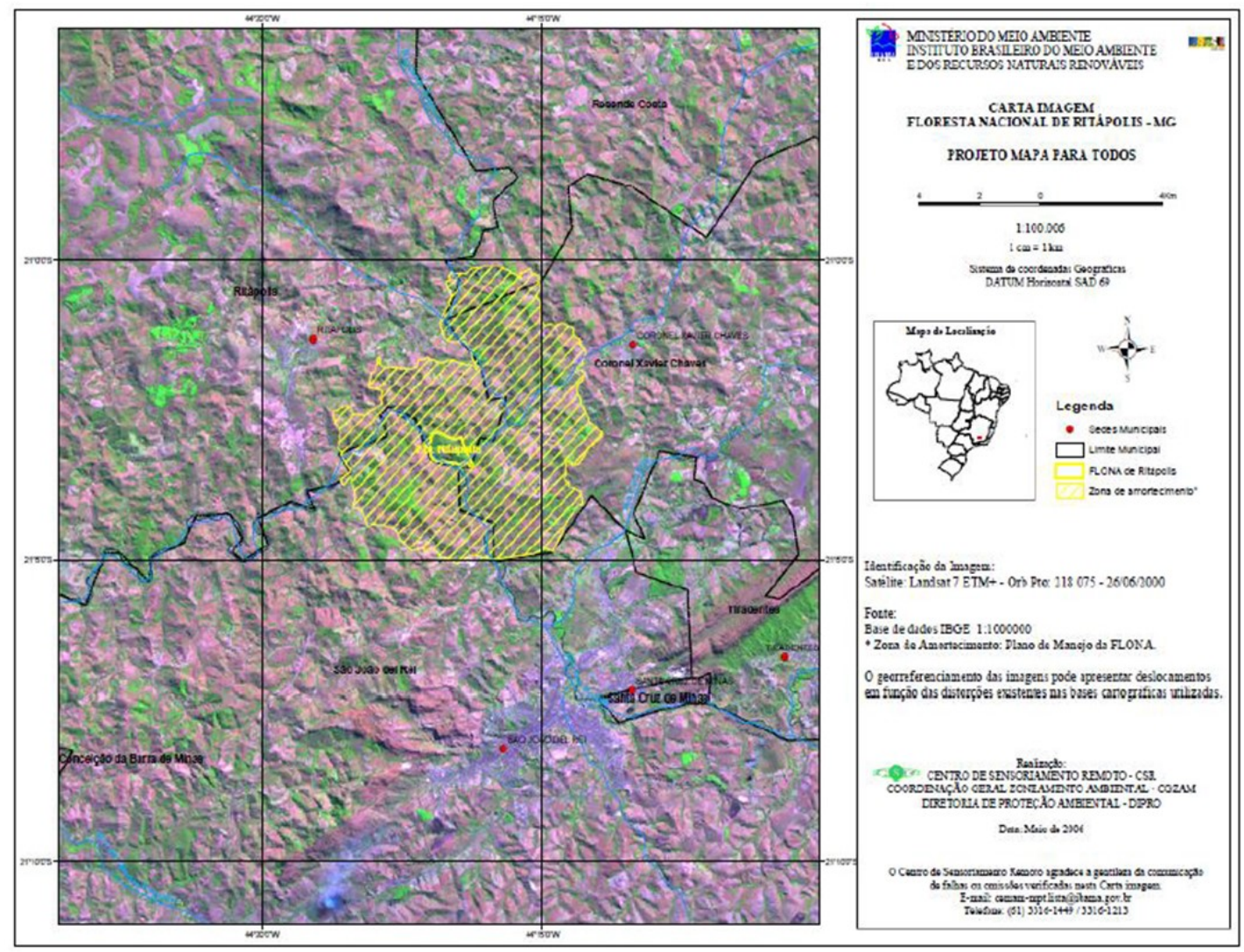

Figura 1 - Localização da Floresta Nacional de Ritápolis (MG).

Fonte: Ministério do Meio Ambiente.

A FLONA possui ao seu redor uma Zona de Amortecimento, que é uma área estabelecida ao redor de uma UC com o objetivo de amortecer os impactos negativos das atividades que ocorrem em seu entorno, como: ruídos, poluição, espécies invasoras e avanço da ocupação humana, especialmente nas unidades próximas a áreas intensamente ocupadas.

O Sistema Nacional de Unidades de Conservação da Natureza (SNUC) - regulamentado através da Lei $\mathrm{N}^{\circ}$ 9.985, de julho de 2000 - define que a Zona de Amortecimento é o "entorno de uma unidade de conservação, onde as atividades humanas estão sujeitas a normas e restrições específicas, com o propósito de minimizar os impactos negativos sobre a unidade".

Além da criação de estradas, para fins de interligação de povoados, distritos cidades, outro impacto antigos foi a implantação da ferrovia do aço, gerenciada pela empresa MRS Logística, que atravessa um trecho de 1,05 km da Floresta Nacional (BRASIL, MMA, 2000). Conforme o plano de manejo desta UC trata-se de uma área conflitante, mesmo considerando que o empreendimento em questão tenha sido implantado antes do registro oficial da FLONA, o que requer medidas de compensação ambiental. 
Ademais, na zona de amortecimento da FLONA de Ritápolis existem relatos de diversos problemas existentes entre os moradores, que tiram o sustendo da terra e as entidades responsáveis por fiscalizar a aplicação da legislação específica para essas zonas de amortecimento. Nesse sentido, tem-se de um lado a legislação e a proposta preservacionista regulamentar e, de outro, a presença de moradores que sobrevivem mediante as atividades associadas ao uso do solo e dos recursos naturais ali existentes.

Nessa pesquisa são utilizados elementos teóricos e práticos de análise da percepção ambiental de uma amostra de diferentes atores sociais localizados no entorno da FLONA de Ritápolis, situadas em sua Zona de Amortecimento.

\section{PROCEDIMENTOS METODOLÓGICOS}

A metodologia adotada neste trabalho consiste principalmente na realização de entrevistas semiestruturadas baseadas em conversas com lideranças e/ou residentes mais antigos nas imediações da FLORA de Ritápolis. Portanto, trata-se de uma pesquisa qualitativa onde foram consideradas também as observações diretas com o intuito de melhor análise e compreensão do tema de estudo.

Enquanto procedimento metodológico, a realização de entrevistas, permite ao pesquisador maior flexibilidade e dinâmica à abordagem do tema - por meio de um roteiro amplo e flexível, que alcance a contextualização dos entrevistados e a ordenação específica das perguntas, de acordo com cada situação estabelecida em campo e de acordo com as singularidades de cada entrevistado.

Desta forma, o questionário é visto como um artifício de pesquisa bem aceito por parte dos respondentes, no entanto, ter certos cuidados na concepção do instrumento, especialmente com o vocabulário, com o tempo de duração e com o local e horário adequados, são pontos de relevância, para evitar possíveis perturbações.

$\mathrm{O}$ instrumento aplicado nesta pesquisa foi composto pelas questões abaixo. Algumas questões indicativas do perfil dos respondentes e outras (abertas e fechadas) para que, ao serem respondidas, evitassem ambiguidades, possibilitando a avaliação livre e intuitiva, identificando assim, a imagem ambiental relaciona à área de estudo.

1. Quais atividades são desempenhadas no entorno da "FLONA"?

2. As atividades desempenhadas nesta área são para consumo familiar ou se destina a geração de renda, por meio de comercialização?

3. Na sua opinião, qual a relação entre a população e a Unidade de Conservação? Conflito ou passividade? 
4. Na sua opinião, esta Unidade de Conservação é vista como um benefício ou problema para os residentes do seu entorno?

5. Você (ou alguém) já foi notificado ou penalizado judicialmente por alguma atividade considerada irregular pelos gestores da FLONA?

6. Existe algum relato, de algum fato inesperado, que prejudicou a sua produção e, que nada pudesse ser feito para contornar a situação, por causa das leis ambientais?

( ) $\operatorname{sim}$ ( ) não

7. Você considera que certas práticas como a criação de animais, caminhadas, circuitos de bicicletas ou motos oferecem algum tipo de risco a Unidade de Conservação?

( ) $\operatorname{sim}$ ( ) não

8. Na sua opinião, a população do entorno do da FLONA tem contribuído para a sua preservação?

( ) $\operatorname{sim}$ ( ) não

9. Você considera que a existência da FLONA implica em quais restrições a população do seu entorno?

A natureza dos questionários foi impessoal e padronizada, buscando assegurar a uniformidade e o anonimato dos respondentes, para garantir a sua livre opinião.

Foram aplicados 15 questionários em pontos aleatórios, dentro da Zona de Amortecimento da FLONA. A amplitude da amostragem se deu em função do número de residentes (LEVIN, 1987; LEVINE, 2000). Também foi realizada uma revisão bibliográfica e documental, para buscar outros possíveis parâmetros de análise.

Por fim, sabendo-se que os espaços são diferentes e possuem características próprias, considerou-se que, ao longo do trabalho poderia surgir a necessidade de se criar uma metodologia própria melhor adaptada a esse universo pesquisado. Nesse sentido, para alcançar os objetivos propostos neste trabalho se fez necessário abordar a percepção ambiental dos diferentes atores sociais que vivem no entorno da FLONA e sua zona de amortecimento, a partir dois fatores: no campo normativo, a aplicação de leis e decretos, para a criação e manutenção de uma área de uma UC; e as condições, impactos, benefícios e obstáculos que possam surgir na vida dos moradores, residentes no entorno desta área, sem perder de vista os seus projetos, emoções, percepção e impressões acerca deste lugar.

Os dados das questões objetivas serão dispostos em forma de gráficos, deste modo definindo um diagnóstico da população alvo da pesquisa. Em se tratando das questões abertas, preliminarmente as respostas serão codificadas alfanumericamente de maneira a facilitar $o$ entendimento e sua localização em caso de revisão. 


\section{FUNDAMENTAÇÃO}

\subsection{Florestas Nacionais: Breve Contextualização}

No Brasil, atualmente existem 67 Florestas Nacionais (FLONAs), das quais três estão situadas no estado de Minas Gerais, nos municípios de Paraopeba, Passa Quatro e Ritápolis. Estas UC são administradas pelo Instituto Chico Mendes de Conservação da Biodiversidade (ICMBio), criado através da lei 11.516, de 28 de agosto de 2007 e vinculado ao Ministério do Meio Ambiente (MMA). Trata-se de uma “[...] área com cobertura florestal onde predominam espécies nativas, visando o uso sustentável e diversificado dos recursos florestais e a pesquisa científica. É admitida a permanência de populações tradicionais que a habitam desde sua criação. (BRASIL, s/d) ${ }^{1}$

Apesar das FLONAs serem de posse e domínio público no seu modelo de gestão é permitido o uso sustentável dos seus recursos, para fins de pesquisa, desde que se cumpra o objetivo que é a proteção e conservação da biodiversidade. Além disso, não é vetada a possibilidade de edificações em seu entorno, desde que a propriedade atenda aos requisitos apresentados no seu plano de manejo ${ }^{2}$. Também, cabe considerar que nem todos os biomas brasileiros possuem florestas nacionais e, com exceção da Amazônia, as demais unidades de conservação ${ }^{3}$ dificilmente alcançam os 10.000 ha.

$\mathrm{Na}$ FLONA, a visitação ou demais atividades vinculadas ao turismo de natureza (ou ecoturismo) não são restritas, pelo contrário. No entanto, o acesso a cada UC está condicionado a um plano de manejo específico, documento este elaborado de acordo com o perfil de cada área, a fim de minimizar ao máximo os impactos da intervenção antrópica naquele meio. Além disso, o

[...] plano de manejo também inclui medidas para promover a integração da UC à vida econômica e social das comunidades vizinhas, o que é essencial para que implementação da UC seja mais eficiente. É também neste documento que as regras para visitação da são elaboradas. (BRASIL, s/d). ${ }^{4}$

A FLONA de Ritápolis foi criada em 1999, mediante o Decreto de 21 de setembro. Sua sede está localizada na Fazenda do Pombal, a 12 quilômetros do município de São João del-Rei, sentido Ritápolis, cujo principal acesso se dá através da rodovia BR-494 (saída no Km 191 à direita, em trecho não pavimentado). Trata-se da menor unidade de conservação do país, com uma área de

\footnotetext{
${ }^{1}$ Disponível em: <http://www.mma.gov.br/areas-protegidas/unidades-de-conservacao/categorias>

${ }^{2}$ Após a criação de uma UC, o plano de manejo deve ser elaborado em um prazo máximo de cinco anos. Toda UC deve ter um plano de manejo, que deve ser elaborado em função dos objetivos gerais pelos quais ela foi criada.

${ }^{3}$ Publicado em Unidades de Conservação. Disponível em: https://uc.socioambiental.org.

${ }^{4}$ BRASIL, REPÚBLICA FEDERATIVA DO BRASIL, Ministério do Meio Ambiente. Plano de Manejo. Disponível em: < http://www.mma.gov.br/areas-protegidas/unidades-de-conservacao/plano-de-manejo $>$. Acessado em: 10 out. 2018 .
} 
89,5 hectares e com uma zona de amortecimento de 4.715 hectares, que em sua totalidade abrange os municípios de São João del-Rei, Ritápolis e Coronel Xavier Chaves (Figura 02).

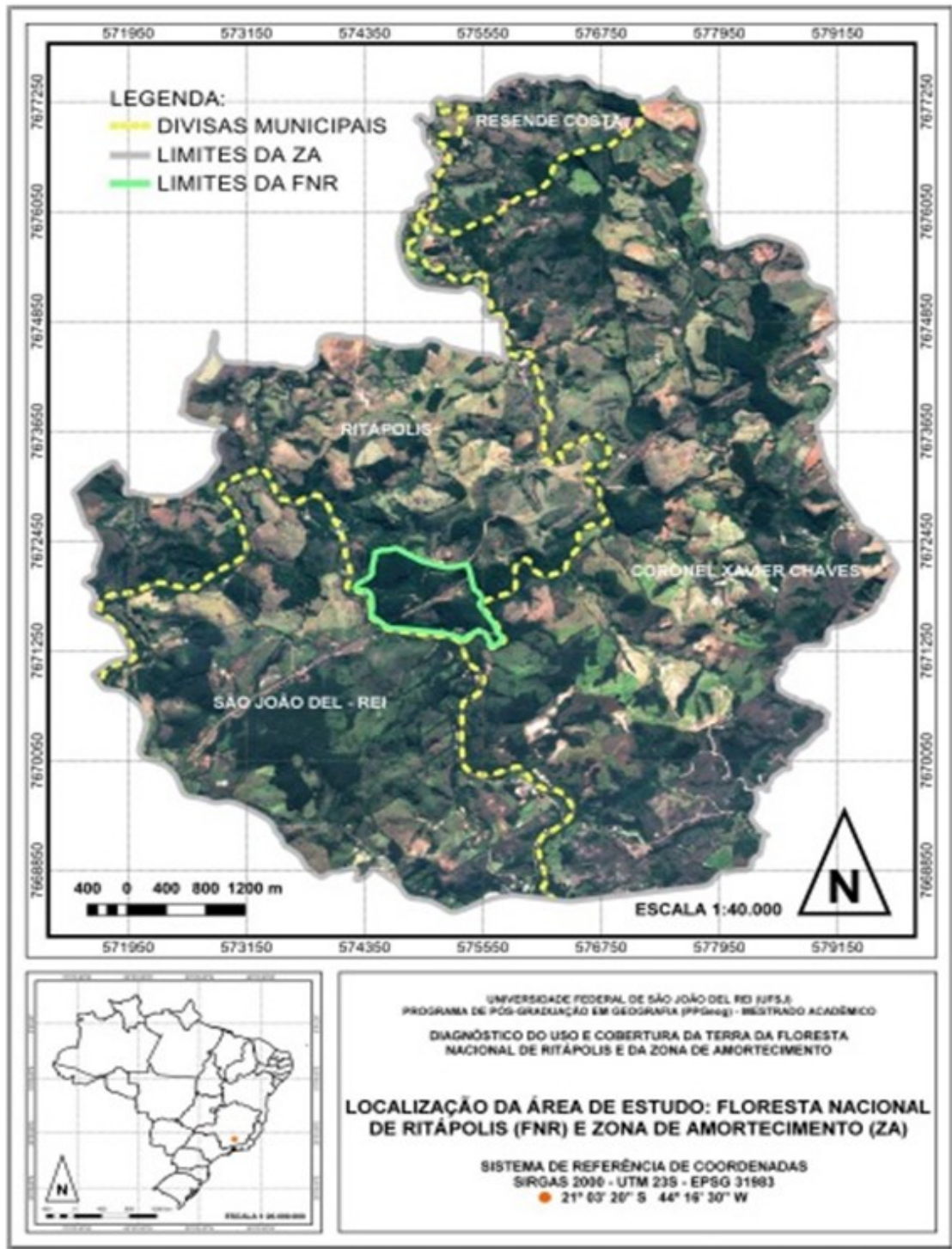

Figura 2 - Localização da Floresta Nacional de Ritápolis com o Recorte da sua Zona de Amortecimento.

Fonte: Souza, (2017).

O sítio onde foi estabelecida a sede da FLONA de Ritápolis, também reúne elementos históricos de importância nacional, pois abriga as ruínas de casa onde nasceu o inconfidente Joaquim José da Silva Xavier, o então Tiradentes (1746-1792), além do que restou do engenho de cana de açúcar daquele período, atraindo turistas de várias partes do país (Figura 3). No local, existem três trilhas que são: Trilha das Macaúbas, Trilha da Ferrovia e Trilha do Rio das Mortes.

[...] As trilhas das Macaúbas e Ferrovia atualmente são utilizadas como recurso didáticopedagógico para o ensino e a prática de Educação Ambiental, visando os significados e as características do ambiente. A trilha do Rio das Mortes atualmente está desativada por ser rota de fuga de pescadores e caçadores que invadem a unidade de conservação (FERREIRA, et. al., 2016, p. 721). 


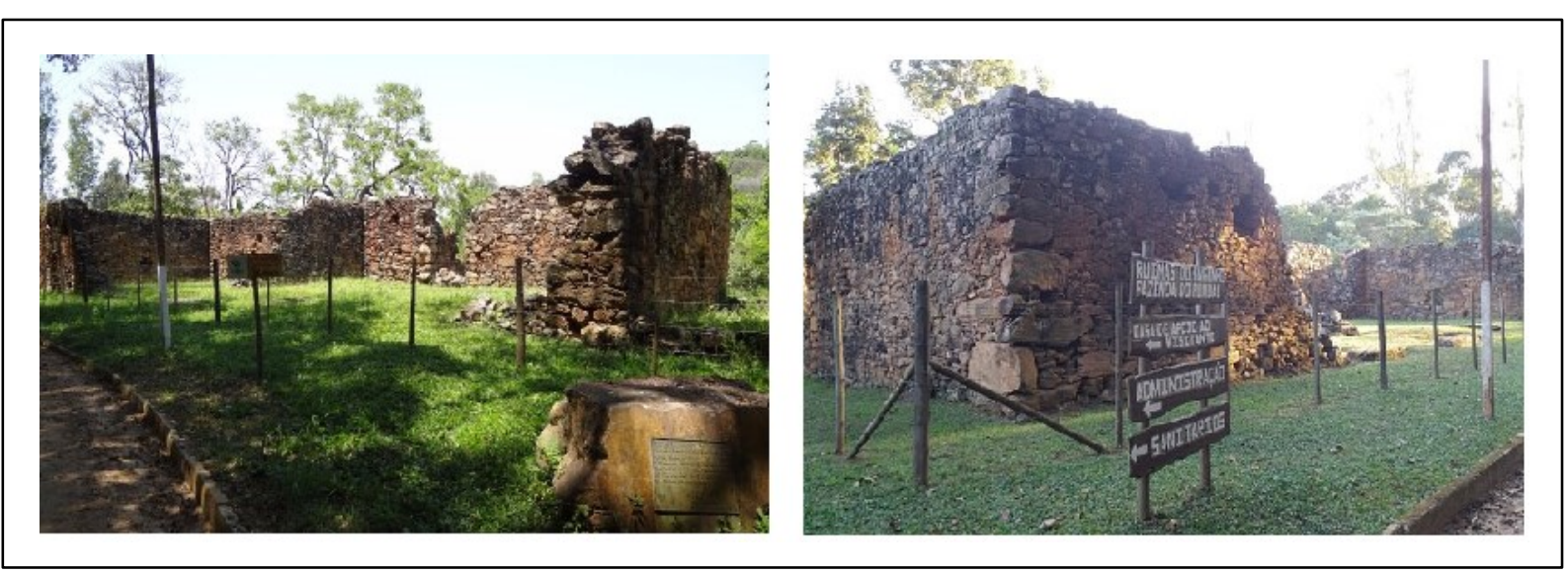

Figura 3 - Localização da área de estudo. Ruínas da Fazenda do Pombal, Ritápolis (MG). Fonte: Autores (2019).

Segundo o Plano de Manejo (IBAMA, 2005) a caracterização do uso e ocupação do solo da FLONA de Ritápolis se resume da seguinte forma:

- 36,94 há de floresta estacional semidecidual (41,45\%);

- $\quad 25,93$ há de campo sujo e cerrado $(29,10 \%)$;

- 2 há de reflorestamento com espécie Eucalyptus saligma (2,24\%);

- 8,72 há de área de empréstimo e de bota-fora (9,78\%);

- 5,51 há de sede administrativa, núcleo residencial e remanescentes históricos $(6,16 \%)$;

- 10,03 há utilizados pela ferrovia $(11,25 \%)$.

Conforme disposto no plano de Manejo da FLONA, a porção urbanizada da UC apresenta uma área de 4,93 ha $(5,52 \%$ de sua área total). Trata-se de uma área reservada as edificações existentes e os espaços de lazer, que, além de obedecerem ao padrão arquitetônico proposto pelo plano de manejo precisa obedecer a alguns critérios de segurança, como por exemplo, a presença de extintores em todas as edificações (BRASIL, MMA, 2000).

Portanto, considerar a presença desses moradores situados dentro dos limites da UC, ou em seu entorno, implica na necessidade de reconhecer que ao residirem nesses locais, estarão consequentemente, dentro da zona de amortecimento da FLONA. Portanto, precisam se enquadrar nos requisitos necessários para a sua manutenção no local; o que de certa forma implicaria em conflitos, tendo em vista a sua percepção e modos de viver.

\subsection{Percepção Ambiental: Entre o Ideal e o Real}

Nesta pesquisa, o debate acerca da percepção ambiental, segue através as orientações do geógrafo sino-americano Yi-Fu-Tuan $(1980 ; 1983 ;$ 2012) e da brasileira Lívia de Oliveira (1977), se 
mostrando a mais adequada para compreender as dinâmicas socioespaciais, a partir da experiência dos sujeitos envolvidos no estudo. Nesse sentido, os moradores situados, no entorno da FLONA de Ritápolis se tornaram os atores sociais deste processo de investigação, considerando que através das suas práticas cotidianas é possível construir nesses lugares uma relação de topofilia, que para Tuan (2012, p. 79) “[...] assume muitas formas e varia muito em amplitude emocional e intensidade".

Segundo Tuan (1983), os traços comuns em percepção ocorrem através dos sentidos da visão, olfato, tato e audição. Assim, é possível pensar o espaço e o lugar, através da experiência, conciliando o conhecimento científico aos saberes construídos empiricamente.

Na experiência, o significado de espaço frequentemente se funde com o de lugar. "Espaço" é mais abstrato do que "lugar". O que começa como espaço indiferenciado transforma-se em lugar à medida que os conhecemos melhor e o dotamos de valor [...] As ideias de "espaço" e "lugar" não podem ser definidas uma sem a outra. A partir da segurança e estabilidade do lugar estamos cientes da amplidão, da liberdade e da ameaça do espaço, e vice-versa. Além disso, se pensamos no espaço como algo que permite movimento, então lugar é pausa; cada pausa no movimento torna possível que localização se transforme em lugar (TUAN, 1983, p.06).

Nas considerações deste autor, é possível compreender que a construção social dos lugares e suas particularidades giram em torno de uma visão de mundo (individual ou coletiva), produzidas através da sensibilidade, do cognitivo e da percepção, incorporando modos de ser e fazer, através de atitudes e valores (TUAN 1982; 2012). É nesta perspectiva que buscamos desenvolver esta pesquisa.

No caso da FLONA de Ritápolis, a percepção ambiental é vista como um importante instrumento para a efetiva gestão da UC, pois permite analisar o conhecimento, os valores e as atitudes da população e/ou dos atores sociais, em relação a uma determinada área (FERREIRA, 2005). Ela é formada por aspectos inerentes ao próprio indivíduo, como por exemplo, os aspectos educacionais e culturais, introduzidos pela sociedade e os afetivos e sensitivos, que têm origens nas relações do observador com o ambiente.

A Percepção Ambiental também é processo e resultado ao mesmo tempo. Como processo é o ponto de partida para o conhecimento ambiental, como resultado pode significar todo conhecimento adquirido a respeito (PINTO, 2014). Vê-se assim a importância de se conhecer e reconhecer as diferentes percepções ambientais da comunidade, visando compreender as diversas formas de interação no meio ambiente e como estas se refletem na realidade da comunidade e mais especificamente na UC. 


\section{RESULTADOS E DISCUSSÕES}

Neste item, apresentamos as informações obtidas através do levantamento realizado em campo, ocorrido ao longo do mês de setembro de 2019. A aplicação do questionário ${ }^{5}$, com perguntas semiabertas se mostrou importante pois, possibilitou o entrevistado comentar sobre a questão apresentada. Para o pesquisador a importância desta estratégia está na possibilidade de apresentar as informações por meio de gráficos, além de reforçar os resultados por meio das justificativas, descrições, discussões e relatos dos sujeitos envolvidos no estudo.

Ao longo das atividades de campo, observou-se que a maioria dos entrevistados apresentavam idades entre 40 e 80 anos e 5 a 40 anos de moradia. Grande parte dos entrevistados se declararam aposentados ou donos de pequenas pousadas e/ou bares. Esta caracterização, somadas as conversas realizadas nos permitiu constatar que o distanciamento da área urbana e o contato com a natureza se refletia em qualidade de vida, sendo a maior motivação de permanência no local.

No local pesquisado, foi possível observar que a maioria das casas eram dispersas, e que várias situavam-se próximas às margens do Rio das Mortes ou do Rio Santo Antônio. Apesar da pouca distância entre as residências os entrevistados apresentaram contrastes significativos em suas respostas, dado que o seu modo de vida e as condições de moradia em uma UC, por si só representam uma relação diferenciada, pois demanda maior colaboração com a preservação do meio natural, que ali se faz presente. Desta forma, os objetivos e metodologia e métodos empregados no decorrer da pesquisa nos permitiram alcançar os resultados que serão apresentados a seguir.

No primeiro momento, para analisar o grau de compreensão dos moradores acerca do local de moradia, frente às condições e normas diversas especificadas para a sua manutenção no lugar foi perguntado sobre o que é uma UC (Figura 4).

\section{Você sabe o que é uma Unidade de Conservação?}

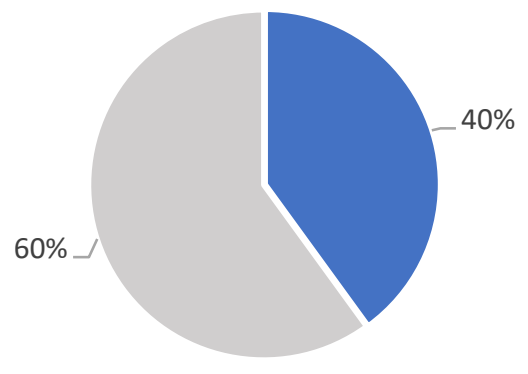

• Sim $\square$ Não

Figura 4 - Respostas sobre a questão: Você sabe o que é uma Unidade de Conservação?

Fonte: Diário de campo, (2019).

\footnotetext{
${ }^{5} \mathrm{O}$ questionário seguirá em Anexo.
} 
Através do contraste de opiniões apresentadas na Figura 4 foi possível observar que mais da metade dos moradores entrevistados não têm conhecimento acerca do que seja uma UC, mesmo residindo nela. A justificativa para esta questão está muitas vezes associada ao fato de considerarem que somente nas imediações da Fazenda do Pombal (sede da FLONA) que se tem a unidade propriamente dita. Por isso, aos arredores foi considerado pela maioria dos entrevistados uma área rural, de acesso à Floresta Nacional.

Um fato que chamou a atenção ocorreu durante a segunda pergunta, na busca de compreender se o entrevistado tinha consciência de estar dentro da Zona de Amortecimento de uma UC (Figura 5). Em princípio, observou-se uma contradição, visto que, por mais que a maioria tivesse conhecimento de estar situado em uma reserva de tal perfil, não havia o conhecimento das suas especificidades e restrições de uso.

\section{Você sabia que a sua residência está situada em uma Unidade de Conservação?}

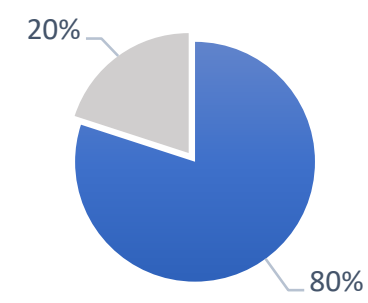

- Sim Não

Figura 5: Respostas sobre a questão: Você sabia que a sua residência está situada em uma Unidade de Conservação. Fonte: Diário de Campo, PEREIRA (2018).

Apesar da maioria dos entrevistados ter demonstrado maior conhecimento sobre o fato de residir em uma UC, cabe considerar que os moradores mais antigos que apresentaram esta consciência, pois também demostraram uma relação direta de zelo e identidade com o seu local de moradia, além de considerar a potencialidade dos seus recursos para a qualidade de vida, fazendo da preservação uma "moeda de troca". Por outro lado, também foi possível observar uma parcela dos entrevistados, que não demostrou relação de afetividade com o lugar.

Os entrevistados também demonstraram reconhecimento quanto à importância da FLONA, pois segundo eles fatores como a conservação da biodiversidade, aproximação da população local à questão ambiental, contato com a natureza, a qualidade de vida e do ar mediante a preservação da natureza são o produto de uma floresta bem cuidada. Além disso: 
A importância de termos uma Unidade de Conservação, reconhecida a nível nacional, está inclusive na vantagem econômica para a região, e do patrimônio histórico de igual valor, na cultura contida nesses locais, embora não haja tanto incentivo para a sua manutenção. (Fala de um morador residente nas proximidades da FLONA/Ritápolis, 2018, s/n).

No entanto, a relação entre população e a FLONA nem sempre se apresenta de forma pacífica, pois também foram registradas situações conflituosas entre os moradores e os fiscais ambientais. Ou seja, questões diversas, consideradas infrações ambientais, que baseadas em leis resultavam em multas, por "uso inadequado do solo", tais como edificações em locais de área inferior ao plano de manejo, a utilização de armas, construção de muros de cimento, ou mesmo a retirada de madeira da mata nativa, que também são proibidos (Figuras 6 e 7).

\section{Você tem conhecimento de conflitos entre a população} residente e a FLONA, devido as restrições de uso do solo?

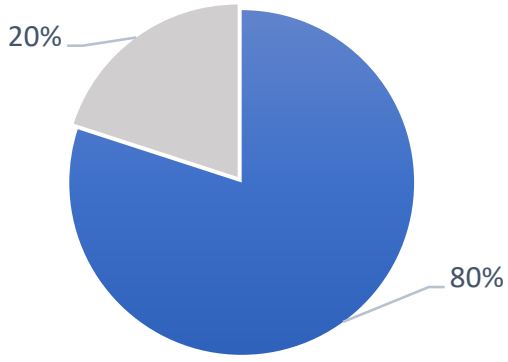

Figura 6: Respostas sobre a questão: Você tem conhecimento de conflitos entre a população residente e a FLONA, devido às restrições de uso do solo?

Fonte: Diário de Campo, PEREIRA (2019).

\section{Você já foi multado, em decorrência de atividades consideradas irregulares pela gestão da FLONA?}

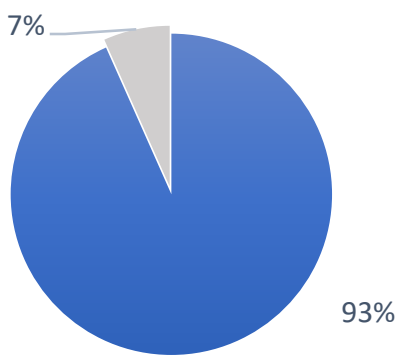

घ Sim $\square$ Não

Figura 7 - Respostas sobre a questão: Você já foi multado, em decorrência de atividades consideradas irregulares pela gestão da FLONA?

Fonte: Diário de Campo, (2019). 
A Figura 7 apresenta o quantitativo de entrevistados que já foram penalizados, com multas ou advertências, pelos órgãos ambientais, responsáveis pelo gerenciamento da UC, em decorrência de alguma atividade considerada irregular. Dentre os fatos é possível destacar, prisão de armas, notificações, advertências, multas, além de medidas de compensação ambiental, devido ao corte de árvore nativa; reformas e construções em edificações de área inferior a dois hectares, construções irregulares, caça e pesca foram as causas mais frequentes registradas em campo.

Nesse ponto, cabe considerar que a maioria dos entrevistados não apresentou repúdio ou resistência às demandas para a preservação da diversidade local. O que foi questionado é a falta de diálogo entre a administração da UC (ICMBio) e a população propriamente dita; o que poderia evitar transtornos para ambos. Sobre a restrição de certos tipos de uso do solo alguns disseram:

Se não houvesse restrição de venda de lotes de menor tamanho, poderia fazer um "pé de meia" para garantir o meu conforto da velhice. [...] Apesar de concordar com o rigor das leis ambientais, considero também que algumas surgem somente para causar transtorno, e pouca ou nenhuma melhoria, para a população, como é o caso da obrigatoriedade da construção de um fossa séptica, na medida que no município por onde passa o Rio das Mortes (São João del-Rei) não existe sequer tratamento de esgoto. Assim, nós que moramos no seu curso baixo (jusante) é que recebemos as águas poluídas pelo esgoto da cidade; (Fala de moradores residentes nas proximidades da FLONA/Ritápolis, 2018, s/n).

Outra reivindicação da população está na falta de segurança, sobretudo em termos de trânsito, haja vista que os carros trafegam em alta velocidade pelas estradas e os moradores, por diversas vezes, foram impedidos de construir quebra-molas. Somadas a isso, a soltura de cachorros no local também é constante e os moradores além de terem seus animais (galinhas, patos, etc.) caçados por eles, não podem tomar nenhuma providência, sem o consentimento dos órgãos ambientais atuantes na localidade.

Apesar da ocorrência de conflitos entre a população e os órgãos ambientais, os primeiros ainda consideram positiva a permanência no local. De modo geral, a tranquilidade e a qualidade de vida, a facilidade de acesso entre os povoados visitados às cidades de São João del-Rei e Ritápolis faz com que o estilo de produção e uso do solo, sejam destinados apenas às atividades de subsistência, por meio da produção de hortaliças, pequenos pomares, criação de animais, atividades de pesca (com raras exceções); haja vista que os demais itens de consumo básico são facilmente adquiridos no mercados urbanos. Além disso, segundo os entrevistados, também são realizadas trocas de produtos entre os vizinhos, reforçando a relação de proximidade.

Nesse percurso, também for perguntado se o entrevistado considera que certas práticas como a criação de animais, pesca, caça, trânsito de veículos oferecem algum tipo de risco à UC, o que pode ser observado na Figura 8, que segue abaixo. 


\section{Práticas como a criação de animais, pesca, caça, trânsito de veículos oferecem algum tipo de risco a Unidade de Conservação?}

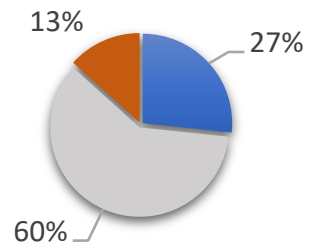

— Sim não $\square$ Outros

Figura 8: Respostas sobre a questão: Práticas como a criação de animais, pesca, caça, trânsito de veículos oferecem algum tipo de risco a Unidade de Conservação?

Fonte: Diário de Campo, (2019).

A justificativa para a maioria dos entrevistados considerarem que a criação de animais e o trânsito de veículos não oferecerem risco a UC se deve ao fato de ambos acreditarem que as atividades quando ocorrem de forma intensa, independente de qual for será danosa. No entanto, se o tráfego de veículos for condicionado as leis ambientais, para evitar o excesso de gases lançados ou a população sonora, ou a criação de animais for controlada não haveria risco.

Por último, foi perguntado se, de acordo com a percepção do entrevistado, a população residente no entorno da FLONA tem contribuído para a sua preservação, o que pode ser observado na Figura 9.

\section{Na sua opinião, a população residente no entorno da FLONA tem contribuído para a sua preservação?}

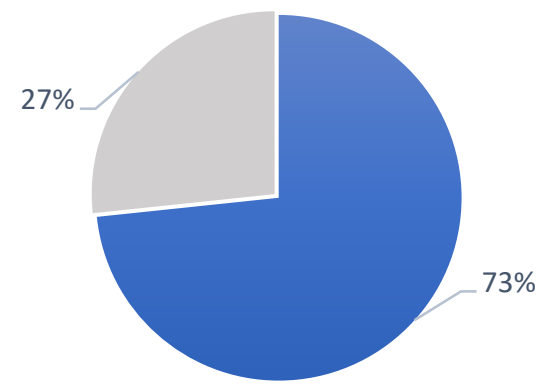

匹 Sim $\square$ Não

Figura 9 - Respostas sobre a questão: Na sua opinião, a população entorno da FLONA tem contribuído para a sua preservação?

Fonte: Diário de Campo, 2018.

Dentre as considerações de consenso positivo, foi possível observar que o fato de todos os moradores estarem situados naquele local em busca de melhores condições de vida e contato com a natureza, naturalmente implicaria na reciprocidade entre os sujeitos envolvidos: "é cuidar de quem cuida de nós", como relatou certo morador. 
Por outro lado, as considerações de consenso negativo, se justificam, segundo os entrevistados no fato de nem todos se preocupem com a conservação do local, por considerarem que esta é uma obrigação da gestão da FLONA, por isso mesmo já iniciam certas infringências como é o caso das construções e loteamentos em áreas inferiores ao previsto no plano de manejo.

\section{CONSIDERAÇÕES FINAIS}

A percepção ambiental é um elemento fundamental identificar e analisar os conflitos e as contradições estruturadas mediante a lei e a sociedade. Este estudo se desenvolveu a partir da percepção ambiental dos moradores residentes na área de amortecimento da FLONA de Ritápolis (MG), os mecanismos de sobrevivência, a relação entre sujeito e lugar, sem perder de vista as contradições encontradas, que por si só apresentaram uma densidade de eventos, no ponto de vista legal e cultural. Os impasses e desafios encontrados no decorrer da pesquisa nos levaram considerar a falta de diálogo e ações participativas de cunho ambiental, tendo em vista que muitas ações punitivas têm sido aplicadas antes mesmo de uma ação educativa (preventiva) o que tem gerado perturbações no ambiente natural e conflitos de ordem social, mais especificamente entre a população e os gestores da UC escolhida para o estudo.

No decorrer da pesquisa a principal contradição encontrada centrou-se no distanciamento entre as leis e a população situada no entorno da FLONA, muitas vezes justificadas pela falta de publicidade de informações que especifiquem as condições de construção para as áreas residenciais situadas no local.

Considerar a preservação ambiental do parque e a manutenção da biodiversidade local como um compromisso coletivo foi um consenso entre todos os entrevistados que participaram do estudo, que inclusive almejam melhorias e métodos de preservação deste patrimônio. No entanto, o uso de certas atividades agrícolas, criação de animais, a ampliação das edificações, áreas de construção civil em terrenos menores do que o previsto no plano de manejo da UC se mostraram conflituosas, sobretudo no que tange a ação do poder público e a população local.

De modo geral, observou-se que existe um consenso entre os entrevistados sobre a necessidade de preservação ambiental. Por outro lado, foi possível constatar as penalidades e as restrições aplicadas a população poderiam ser produto de um diálogo, que promovesse recursos e ações consensuais para assegurar a integridade da FLONA e dos residentes situados em seu entorno.

Além disso, esses moradores demonstraram uma relação de cuidado com o lugar, que lhes transmitiam tranquilidade e segurança, o que pôde ser observado por meio de suas falas. Nesse 
sentido, residir na FLONA deixou de ser um capricho, em vista da construção de uma nova identidade.

Conforme relatado por moradores, de modo geral, o aumento no número de residências é uma tendência e produto de novas ações comerciais, que se sustentam através do discurso da vida na roça, contato com a natureza, promovendo a sustentabilidade (discurso verde); que são divulgados por construtoras que almejam lotear esses espaços, atribuindo alto valor de mercado. Em contrapartida, observou-se também a ampliação e rigor nos serviços de combate às ocupações ilegais, o que têm desencadeados novos conflitos.

Portanto, este trabalho apresentou alguns dos desafios e contradições que se estabelecem no âmbito do território: do ponto de vista social e ambiental, em que ambos permeiam o campo da legalidade, porém, não estão isentos de novos desfechos.

$\mathrm{Na}$ atualidade, apresentar tais questionamentos, por meio de estudos e análises, que evidenciem as contradições inerentes ao território, sobretudo mediante o distanciamento dos discursos, ambientais, políticos e econômicos; se ilustram através de situações semelhantes a apresentadas nesta pesquisa e não se reduzem a este caso. Portanto, cabe-nos enquanto pesquisador compreender os benefícios, conflitos e contradições existentes entre as leis e seus reais impactos, juntamente com a população, em busca de parcerias e ações públicas, sociais e participativas que, de fato possam repercutir positivamente em nossa sociedade.

\section{REFERÊNCIAS}

ACSELRAD, H. As práticas espaciais e o campo dos conflitos ambientais. in H. Acselrad (org.), Conflitos Ambientais no Brasil, Rio de Janeiro, Relume Dumará / Fundação Heinrich Böll. 2004.

AMORIM FILHO, O. B.; CARTER, H.; KOHLSDORF, M. E. Percepção ambiental: contexto teórico e aplicações ao tema urbano. Belo Horizonte: Departamento de Geografia, 1987. 42p.

AMORIM FILHO. O. B. Os estudos da percepção como última fronteira da gestão ambiental. In: SIMPÓSIO AMBIENTAL E QUALIDADE DE VIDA NA REGIÃO METROPOLITANA DE BELO HORIZONTE, 2., Belo Horizonte. Anais... Belo Horizonte, Associação Brasileira de Engenharia Geológica, 1992.

ICMBIO - Instituto Chico Mendes de Conservação da Biodiversidade. Unidades de Conservação: Categorias. 2018. Disponível em: <http://www.icmbio.gov.br/portal/unidadesdeconservacao $>$. Acesso em: 10 mai. 2019.

BRASIL, REPÚBLICA FEDERATIVA DO BRASIL. Lei no 9.985, de 18 de julho de 2000. Regulamenta o art. 225, $\S 1^{\circ}$, incisos I, II, III e VII da Constituição Federal, institui o Sistema Nacional de Unidades de Conservação da Natureza e dá outras providências. Disponível em: < http://www.planalto.gov.br/ccivil_03/LEIS/L9985.htm>. Acesso em: 28 mar. 2019. 
BRASIL, REPÚBLICA FEDERATIVA DO BRASIL. Decreto de 21 de setembro de 1999. Cria a Floresta Nacional de Ritápolis, no Estado de Minas Gerais, e dá outras providências. Brasília: BRASIL, 1999. Disponível em: <http://pesquisa.in.gov.br/imprensa/jsp/visualiza/index. jsp?jornal=1\&pagina=61\&data=22/09/1999> Acesso em: 02 set. 2019.

BRASIL. Ministério do Turismo (Org.). Destino referência em turismo de estudos e intercâmbio: São João del-Rei - MG. Brasília, 2010. 201 p.

, Lei $\mathbf{n}^{\circ}$ 9985, de 18 de julho de 2000. Regulamenta o art. 225, § 1o, incisos I, II, III e VII da Constituição Federal, institui o Sistema Nacional de Unidades de Conservação da Natureza e dá outras providências. Brasília: BRASIL, 2000. Disponível em: <http://www. planalto.gov.br/ccivil_03/leis/L9985.htm> Acesso em: 03 out. 2019.

, Ministério do Meio Ambiente. Sistema Nacional de Unidades de Conservação

da Natureza (SNUC). Categorias. Disponível em: <http://www.mma.gov.br/areasprotegidas/unidades-de-conservacao/categorias >. Acesso em: 10 out. 2019.

, Ministério do Meio Ambiente. Sistema Nacional de Unidades de Conservação

da Natureza (SNUC). Categorias. Disponível em: <http://www.mma.gov.br/areasprotegidas/unidades-de-conservacao/categorias >. Acesso em: 10 out. 2019.

Ministério do Meio Ambiente. Plano de Manejo. Disponível em: < http://www.mma.gov.br/areas-protegidas/unidades-de-conservacao/plano-de-manejo $>$. Acesso em: 10 out. 2019.

CULLEN, J. R. L.; RUDRAN, R.; VALLADARESPÁDUA, C. Métodos de estudos em Biologia da Conservação \& Manejo da Vida Silvestre. 1. ed. Curitiba: Editora UFRP, 2004. 665p.

FERREIRA, A. C.; FIGUEIREDO, M. A.; SALVIO, G. M. M.; FERNANDES, B. H.; ROCHA, L. C. Estudos Geoecológicos Aplicados ao Manejo da Trilha das Macaúbas na Floresta Nacional de Ritápolis - Minas Gerais. Caderno de Geografia, Belo Horizonte, v. 26, n. 47, p. 714-736, 2016.

FERREIRA, C. P. Percepção Ambiental na Estação Ecológica de Juréia-Itatina. 2005. 135 f. Dissertação (Mestrado em Ciência Ambiental) - Universidade de São Paulo, São Paulo, 2005.

FERREIRA, L. C. Dimensões humanas da biodiversidade: mudanças sociais e conflitos em torno de áreas protegidas no Vale do Ribeira, SP, Brasil. Revista Ambiente \& Sociedade, v. 2, p. 47-66, 2004.

GUimarães, B. M. M.; FILHO, J. A. C.; LEAL, M. C. Paisagem das Vertentes: Caderno 1. São João del-Rei: UFSJ. 2008. 100p.

IBAMA - Instituto Brasileiro do Meio Ambiente e dos Recursos Naturais Renováveis. Plano de Manejo da Floresta Nacional de Ritápolis: diagnóstico e planejamento. Brasília: IBAMA, 2005. Disponível em <http://www.icmbio.gov.br/portal/images/stories/docs-planos-de-manejo/pm> Acesso em: 06 set. 2019.

ICMBIO - Instituto Chico Mendes de Conservação da Biodiversidade. Biodiversidade: Unidades de Conservação. Brasília: ICMBio, 2017. Disponível em <http://www.icmbio.gov.br/portal/ flonade-ritapolis?highlight=WyJyaXRcdTAwZTFwb2xpcyJd> Acesso em: 06 set. 2017.

LEVIN, J. Estatística Aplicada a Ciências Humanas. 2. ed. São Paulo: Harbra, 1987. 124p. 
LEVINE, D. M.; BERENSON, M. L.; STEPHAN, D. Estatística: Teoria e Aplicações usando Microsoft Excel em Português. Rio de Janeiro: LTC, 2000. 92p.

PINTO, D. A. Percepção ambiental no entorno da Reserva Biológica do Poço D'anta: estudo de caso da Escola Estadual Professor Lindolfo Gomes - Juiz de Fora - MG. 2014. 78 f. Monografia (Especialização em Planejamento e Gestão de Áreas Naturais Protegidas) - Instituto Federal de Educação, Ciência e Tecnologia do Sudeste de Minas Gerais, Barbacena, 2014.

OLIVEIRA, L. Contribuição dos Estudos Cognitivos à Percepção Geográfica, Geografia, v. 3, n. 2, p. 61-72, 1977.

PRIMACK, R. B. A primer of conservation biology. 2 ed. Massachusetts: Sinauer Associates, 2000. 319p.

SILVA, T. S.; CÂNDIDO, G. A.; FREIRE, E. M. X. Conceitos, percepções e estratégias para conservação de uma estação ecológica da Caatinga nordestina por populações do seu entorno. Sociedade \& Natureza, Uberlândia, v. 21, n. 2, p. 23-37, 2009.

SOMMER, R.; SOMMER, B. Um Guia Prático Para Pesquisas Comportamentais: técnicas e ferramentas. São Paulo: EPU-EDUSP, 1980.

SOUZA, E. M. Diagnóstico do Uso e Cobertura da Terra na Floresta Nacional de Ritápolis e da Zona de Amortecimento. 2017. 102 f. Dissertação (Mestrado em Geografia) - Universidade Federal de São João del-Rei, São João del-Rei, 2017.

TUAN, Yi-Fu. Topofilia - um estudo da percepção, atitudes e valores do meio ambiente. Londrina: Eduel, 2012.

TUAN, Yi-Fu. Topofilia: um estudo da percepção, atitudes e Valores do Meio Ambiente. Tradução Lívia de Oliveira. 2. ed. São Paulo: Difel, 1980.

TUAN, Yi-Fu. Espaço e lugar: perspectiva da experiência. Tradução Lívia de Oliveira. São Paulo: Difel, 1983 